\title{
Agronegócio e geopolítica do liberalismo transnacional Biodiversidade e soberania alimentar em risco na América do Sul
}

\author{
Elisa Pinheiro de Freitas \\ Universidade Federal de Mato Grosso do Sul, Brasil \\ elisa.freitas@ufms.br
}

\section{Resumo}

Tramas

No atual cenário de mudanças climáticas, verifica-se a crescente demanda por alimentos e energia de baixo carbono, pondo em marcha a disputa pelo controle de recursos essenciais da natureza: solo e água. Observa-se, nos países sul-americanos, o processo de apropriação de parte da renda da terra pelas principais tradings que operam na cadeia produtiva da soja. Com base no levantamento de dados estatísticos a partir de fontes governamentais, corporativas e de revisão de literatura sobre o tema, o objetivo deste artigo é tratar sobre os efeitos do controle corporativo transnacional para agronegócio dos países da América do Sul, bem como as implicações socioespaciais que se manifestam na perda de biodiversidade e na de soberania alimentar.

\section{Palavras chave}

1| agronegócio 2| expansãoda fronteira agrícola $3 \mid$ biodiversidade 4 | soberania alimentar

\section{Cita sugerida}

Freitas, Elisa Pinheiro de (2021). Agronegócio e geopolítica do liberalismo transnacional: biodiversidade e soberania alimentar em risco na América do Sul. Tramas y Redes, (1), 69-84, 100a. DOI: 10.54871/c14c100a 
Tramas y Redes Dic. 2021 $\mathrm{N}^{0} 1$

ISSN en trámite

\section{Palabras clave}

$1 \mid$ agronegocio $2 \mid$ expansión de la frontera agrícola $3 \mid$ biodiversidad $4 \mid$ soberanía alimentaria

\section{Agribusiness and geopolitics of transnational liberalism: biodiversity and food sovereignty at risk in South America}

\begin{abstract}
In the current climate change scenario, there is a growing demand for low-carbon food and energy, setting in motion the dispute for the control of essential natural resources: soil and water. In South American countries, the process of appropriation of surplus value by the main trading companies operating in the soy production chain can be observed. Based on the survey of statistical data from government and corporate sources and literature review on the subject, the aim of this article is to address the effects of transnational corporate control for agribusiness in South American countries as well as the socio-spatial implications that manifest themselves in the loss of biodiversity and food sovereignty.
\end{abstract}

\title{
Keywords
}

$1 \mid$ agribusiness 2| agricultural frontier expansion 3| biodiversity $4 \mid$ food sovereignty 


\section{Introdução}

Desde a consolidação dos Estados Unidos na liderança do capitalismo mundial, após o declínio da União Soviética, o mundo tem sido delineado pela emergência da ordem geopolítica do liberalismo transnacional, que se caracteriza pela hegemonia do mercado autorregulado, conforme explicaram Agnew e Corbridge (1995). Destaca-se que uma dada ordem geopolítica pode ser compreendida como sendo um período histórico-geográfico marcado por um conjunto de regras enraizadas, instituições, atividades e estratégias que dirigem a economia política internacional e influenciam na política doméstica dos Estados Nacionais, em maior ou menor grau.

Sob a geopolítica do liberalismo transnacional, o Estado-nação continua a ser um ator importante na organização do espaço mundial em decorrência de sua centralidade na articulação entre as questões econômicas, sociais e de segurança interfronteiriças. Mas, no modelo de capitalismo atual, as corporações transnacionais - TNCs, sigla em inglês -, as instituições financeiras, as organizações sociais não governamentais, dentre outras, acumularam poder econômico e ampliaram a capacidade de interferir nos destinos das diferentes regiões do mundo, como argumentaram Panith e Gindin (2012).

O liberalismo transnacional fomentou a mudança de natureza dos Estados nacionais, que passaram a operar em rede, sendo um nó num conjunto de outros nós constituídos por atores não estatais e supranacionais:

E, para aumentar a capacidade competitiva de seus países, criaram uma nova forma de Estado - o Estado-rede -, a partir da articulação institucional dos Estados-nação, que não desaparecem, mas se transformam em nós de uma rede supranacional para a qual transferem soberania em troca de participação na gestão da globalização (Castells, 2018, p. 14).

Como ressalta Castells (2018), os Estados nacionais têm atuado em articulação com instituições supraestatais, corporações transnacionais e com outros agentes capazes de influírem a escala internacional. Mas como as ações desses atores impactam os territórios no atual contexto das mudanças climáticas? Observa-se, desde o início do século XXI, a crescente demanda mundial por alimentos e energia de baixo carbono. A Organização das Nações Unidas para Alimentação e Agricultura (FAO) estima que até 2050 a produção agrícola deve ser incrementada em até $60 \%$ de modo a assegurar tanto o abastecimento alimentar quanto o de agrocombustíveis, conforme apontaram Saath e Fachinello (2018).

Por essa razão, a corrida por esses recursos tem gerado disputas entre atores estatais e não estatais, que buscam controlar as regiões do Globo 
com disponibilidade hídrica e terra agricultável com o objetivo de assegurar suprimento alimentar, energético e acumular capital. Decorre desse processo o alargamento da área de produção de commodities valorosas para o mercado global, como a soja e seus derivados, nas regiões do Cerrado brasileiro e do interior da planície do Chaco, que abarca porções dos territórios da Argentina, da Bolívia, do Paraguai e do Uruguai.

Feitas essas considerações iniciais, destaca-se que o objetivo deste artigo é tratar sobre os efeitos do controle corporativo transnacional sobre a cadeia produtiva da soja para os países da América do Sul. Especificamente, busca-se mostrar que a expansão da fronteira agrícola fomentada pelas tradings do agronegócio atinge regiões de grande biodiversidade e concorre para reduzir as áreas destinadas para a produção dos gêneros de primeira necessidade, colocando em risco a biodiversidade e a soberania alimentar na região sul-americana.

Metodologicamente, para o desenvolvimento deste artigo, buscou-se recolher e analisar dados publicados em jornais de circulação nacional e internacional e na revisão de artigos científicos que tratam sobre: i) agentes econômicos que participam da cadeia produtiva da soja (do plantio à agroindústria); ii) expansão da fronteira agrícola para o Cerrado e Planície do Chaco; iii) imposição de barreiras não tarifárias de cunho ambiental pelo conjunto de países que compõe a União Europeia (UE) aos países que expandem a produção agrícola sobre áreas de florestas; e iv) os riscos de perda da biodiversidade e da soberania alimentar a partir da redução da área destinada para as unidades de conservação e à produção de alimentos.

Também se consultou o Projeto de Lei n. ${ }^{\circ}$ 2633/2020, que tramita na Casa Legislativa Federal do Brasil e trata sobre a regularização fundiária de terras desmatadas. Igualmente buscou-se acompanhar a defesa, pela bancada ruralista, da tese do marco temporal para demarcação de terras indígenas no Brasil. Quanto à elaboração dos mapas, utilizou-se o software QGIS 3.16.5, o que possibilitou reunir e analisar os dados espaciais disponibilizados pelas principais tradings que operam na cadeia produtiva da soja, pelo Ministério do Meio Ambiente, da Agricultura e do Instituto Brasileiro de Geografia e Estatística (IBGE), pelo Instituto Nacional de Pesquisas Espaciais (Inpe) e pela organização não governamental MapBiomas. Por fim, o artigo divide-se em três seções. A primeira aborda sobre como se deu o processo de internacionalização, na América do Sul, da cadeia produtiva da soja. A segunda mostra a perda de biodiversidade e de soberania alimentar na região sul-americana à medida que a expansão da fronteira agrícola avança sobre as áreas de florestas e de cultivo de gêneros de primeira necessidade e a terceira busca sintetizar as principais questões tecidas ao longo do artigo. 


\section{Agronegócio e o controle corporativo transnacional sobre a cadeia produtiva da soja na América do Sul}

O comércio, entre outros fatores de circulação que ocorrem através do estransnacionais, o Fundo Monetário Internacional (FMI), o Banco Interamericano de Desenvolvimento (Bird) e o Acordo Geral de Tarifas e Comércio (Gatt) passaram a comandar o processo de mundialização econômica e constituíram-se nos tentáculos dos EUA sobre os países periféricos e semiperiféricos do sistema internacional.

Assim, as décadas de 1980 e 1990 foram marcadas pela ampla adesão, sobretudo dos países da América Latina, à implementação de liberação dos mercados, às privatizações e às medidas de austeridade orçamentária. O conjunto dessas políticas econômicas ficou conhecido como o Consenso de Washington, conforme explicaram Stiglitz (2004, pp. 47-49), Peet (2007, p. 1) e Houtart (2010).

Com uma legislação que passou a favorecer os investimentos estrangeiros, o que pode ser observado em relação ao agronegócio da soja no contexto sul-americano é sua crescente internacionalização, com a participação cada vez mais hegemônica dos players globais nas etapas intensivas em tecnologia - produção de sementes, fertilizantes, máquinas e defensivos agrícolas -, em detrimento das empresas domésticas que dominaram o setor anterior a 1980, conforme explicaram Wesz Junior (2014), Soares (2019) e Medina (2021).

Desde 1995, as grandes corporações exportadoras de commodities agrícolas, como a Archer Daniels Midland (ADM), Bunge, Cargill e Dreyfus, também denominadas de ABCD, têm controlado parte do processo de esmagamento e de exportação da soja in natura produzida na América do Sul. Destaca-se que os produtores brasileiros têm expandido a plantação de soja na Bolívia e no Paraguai. Os argentinos, por sua vez, têm produzido no Uruguai, conforme mostraram Gonzáles (2014), Dos Santos (2017) e Soares (2019). A Argentina continua a beneficiar a soja, exportando produtos com maior valor agregado, como o farelo e o óleo sendo o maior exportador mundial daqueles produtos como destacaram Gonzáles (2014), Cunha e Espíndola (2015), Medina, Guimarães Ribeiro e Madureira Brasil (2015).

No Brasil, a Lei Kandir isenta a exportações de soja in natura, o que tem desencorajado o beneficiamento daquele grão. Levando em consideração toda a cadeia produtiva da soja - do plantio à agroindústria -, o estudo realizado por Medina (2021) demonstrou que, entre 2015 e 2020, a participação de grupos domésticos brasileiros nos segmentos que mais envolvem tecnologia caiu de $40 \%$ para $34,6 \%$. Tal fato leva o Brasil a se concentrar nos fatores básicos de produção, como a terra (13,3\%), a força de trabalho (14\%) e 
os recursos naturais não contabilizados financeiramente (12\%). Este padrão também é verificado na Bolívia, no Paraguai e no Uruguai conforme mostraram Gonzáles (2014) e Dos Santos (2017).

Já as tradings do grupo ABCD e outras controlam no Brasil os $65,4 \%$ do negócio da sojicultura que envolve fatores intensivos em tecnologia. Por esta razão, Medina, Guimarães Ribeiro e Madureira Brasil (2015, p. 6) defendem a verticalização da produção, com a maior participação dos grupos nacionais nos segmentos de tecnologia e de gestão para que os ganhos sejam capilarizados para dentro do próprio país.

A apropriação de parte da renda da terra pelas tradings faz com que os produtores sul-americanos busquem expandir a fronteira agrícola da soja sobre áreas de florestas e de cultivos de gêneros agrícolas de primeira necessidade para compensar as perdas com a escala. Conforme os dados disponibilizados pela Datagro, estima-se que para a safra 2021/2022 a área plantada na América do Sul atinja 62,75 milhões de hectares, o que significa um crescimento de $2 \%$ em relação à safra anterior, cuja área plantada fora de 61,43 milhões de hectares. Quanto à produção, espera-se colher 211,95 milhões de toneladas em 2021/2022, ante os 197,70 milhões do ano anterior, auferindo um crescimento de $7 \%$. Na Tabela 1 , pode ser verificada a participação de cada país da região no agronegócio da soja:

Tabela 1. Produção de soja na América do Sul safra 2021/2022 (em milhões)

\begin{tabular}{|l|c|c|}
\hline País & Área (milhões de hectares) & Produção (milhões de toneladas) \\
\hline Argentina & 16 & 51,27 \\
\hline Bolívia & 1,45 & 3,19 \\
\hline Brasil & 40,57 & 144,07 \\
\hline Paraguai & 3,5 & 10,47 \\
\hline Uruguai & 1,23 & 2,95 \\
\hline América do Sul & 62,75 & 211,95 \\
\hline
\end{tabular}

Fonte: Datagro, 2021; Aprosoja; 2021. Organização: autora

Na Figura 1, pode ser visualizado onde estão localizadas as instalações e escritórios: 
Figura 1. Distribuição geográfica das tradings que controlam a cadeia produtiva da soja na América do Sul

Tramas y Redes Dic. 2021

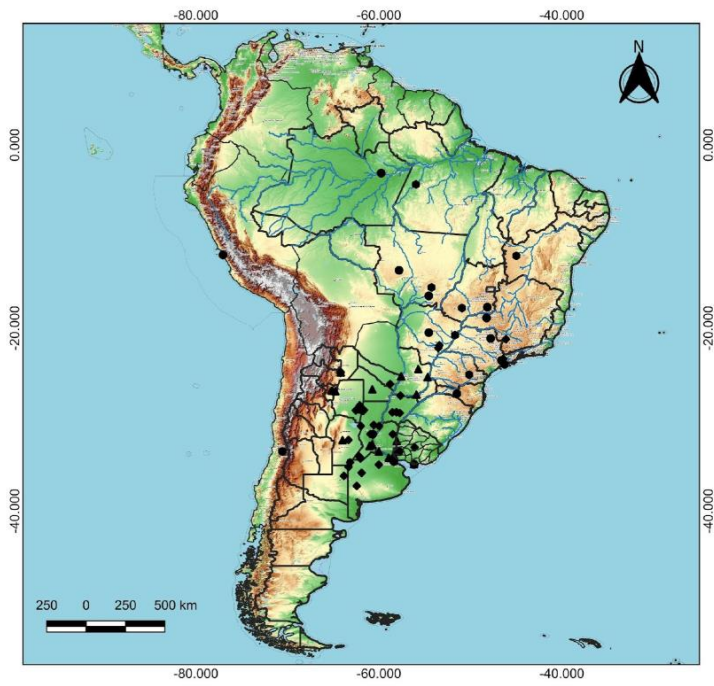

\section{Legenda}

- Unidades da ADM

- Unidades da Bunge

- Unidades da Adecoagro

- Unidades da Cargill Hidrovias

$\square$ Limites territoriais OpenTopoMap

Fonte dos dados: ADM (2021); Bunge (2021): Adecoagro (2021) e Cargill (2021)

\section{(1)}

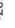

Sistema de Coordenadas UTM Datum SIRGAS 2000/WGS 84 Base cartográfica: IBGE, 2018 Uruguai Administrative Boundary Common Operational Database (COD-AB) Argentina-Departamento Elaboração: autora

Fonte: ADM (2021); Bunge (2021); Adecoagro (2021) e Cargill (2021).

Conforme os dados apresentados na Figura 1, as unidades das principais tradings estão concentradas nas províncias de Santiago del Estero, Corrientes e Entre Ríos (Argentina); e nos estados de Mato Grosso do Sul, Mato Grosso e Goiás (Brasil). Destaca-se ainda que a ADM mantém escritórios em Santiago do Chile (Chile) e em Lima (Peru). O atual modelo de agronegócio da soja que se verifica nos países sul-americanos privilegia a monocultura extensiva, que implica impactos socioespaciais, como a perda da biodiversidade e da soberania alimentar, que serão abordados na próxima seção.

\section{Biodiversidade e soberania alimentar em risco}

Intensificou a pressão internacional para que o governo brasileiro implemente políticas eficazes de proteção à Floresta Amazônica e ao Pantanal em meio ao cenário de mudanças climáticas. Segundo os dados do MapBiomas Fogo, a Amazônia e o Cerrado foram os biomas mais atingidos pelo fogo entre 1985 e 2020, tendo, juntos, 85\% de suas áreas queimadas. Em termos percentuais, o bioma Pantanal foi o mais afetado pelo fogo, tendo acumulado, entre 1985 e 2020, perda de 57\% de sua área pelos incêndios. A partir da plataforma Terra Brasilis-INPE, elaborou-se o mapa que mostra 
Figura 2. Perda de vegetação acumulada nos biomas Cerrado, Floresta Amazônica e Pantanal: 2008-2020
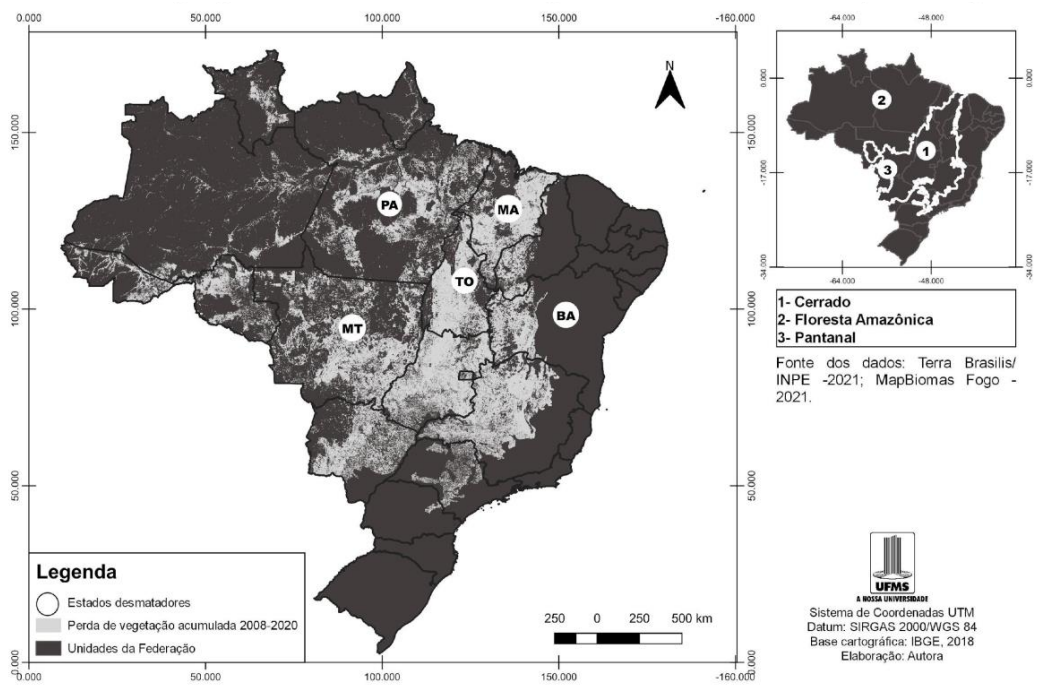

Fonte: Terra Brasilis-INPE/MapBiomas (2021).

Conforme os dados do MapBiomas, o estado de Mato Grosso (MT) acumulou 23,5\% da área queimada, entre 1985 e 2020, ocupando o topo do ranking entre os estados brasileiros. Logo em seguida, destaca-se o estado do Pará com 12,8\% de área queimada, depois o estado de Tocantins com 9,9\%, o estado do Maranhão com 9,3\% e o estado da Bahia com 6,9\%. Quanto ao ranking por municípios, Corumbá - capital do Pantanal - em Mato Grosso do Sul, acumulou no período supracitado 2,2\% de área queimada. Na sequência, vem o município de São Félix do Xingu (PA) com 1,3\%, Formosa do Rio Preto (BA) com 0,8\%, Paranatinga (MT) com 0,7\% e Cáceres (MT) com 0,7\%.

Como se nota, a expansão da fronteira agrícola para a produção de soja, sobre áreas de pastagens degradadas ou não, provoca o deslocamento da pecuária bovina para as franjas da Amazônia e concorre para o desmatamento florestal, conforme demonstraram Houtart (2010, p. 148), Freitas e Queirós (2018). No Uruguai, a pecuária também tem sido deslocada para áreas não cultiváveis e no Paraguai a soja avança sobre regiões de florestas segundo os apontamentos de Gonzáles (2014). 
Assim, a constante incorporação de terras pelo agronegócio coloca em risco os reservatórios de biodiversidade, impacta no modo de vida de populações tradicionais que desenvolvem formas sustentáveis de se relacionarem com o meio e potencializa conflitos entre aquelas e os produtores, como explicou Bernardes (2015). Além disso, desde a implementação do Protocolo de Kyoto, os países signatários, com destaque para aqueles que compõem a UE, têm imposto, aos países exportadores de commodities agrícolas que não adotam práticas sustentáveis no processo produtivo de alimentos e agrocombustíveis, barreiras não tarifárias de cunho ambiental, como explicou Oliveira (2009). Líderes europeus como Emmanuel Macron e Ângela Merkel, por exemplo, se tornaram severos críticos em relação à sojicultura brasileira, pois entendem que os produtores têm desmatado áreas florestais para expandir o plantio.

Com o boom dos agrocombustíveis verificado no primeiro decênio do século XXI, igualmente observou-se a ampliação da área produtiva com cana-de-açúcar no Brasil que, tradicionalmente cultivada na região noroeste do estado de São Paulo e na Zona da Mata Nordestina, se expandiu para o sudeste de Mato Grosso do Sul, de Goiás, de Minas Gerais e do norte do Paraná, de acordo com Freitas (2013). Embora alguns países da UE tenham importado etanol do Brasil para adicionarem à gasolina e reduzirem a emissão dos Gases do Efeito Estufa (GEEs), o ano de 2008 foi marcado por muitos debates, sobretudo em âmbito europeu, quanto à sustentabilidade da produção dos agrocombustíveis.

Conforme as instruções normativas da Diretiva Europeia, cada Estado Nacional que compõe o Bloco Europeu tem autonomia para desenvolver estratégias para a redução das emissões dos GEEs no setor de transporte. Não obstante, se o Estado-membro da UE optar pelo uso de etanol e/ ou de biodiesel importados, deverá se certificar de que o etanol e/ou biodiesel foram produzidos em áreas apropriadas e distantes das regiões de grande biodiversidade - regiões florestais - e que não tenham comprometido a produção de alimentos no interior do país exportador.

Em 2008, o governo brasileiro, com o objetivo de comprovar que a produção de agrocombustíveis não impactaria os biomas Pantanal e Floresta Amazônica, solicitou a várias instituições de pesquisa, como o Instituto Nacional de Pesquisas Espaciais (Inpe), Universidade Estadual de Campinas (Unicamp), Instituto Brasileiro de Geografia e Estatística (IBGE), entre outras, que elaborassem o Zoneamento Agroecológico da Cana-deAçúcar (ZAC).

O objetivo do ZAC era apresentar o mapeamento sobre o território brasileiro, bem como indicar as áreas propícias, tanto para a expansão do cultivo da cana-de-açúcar quanto para a instalação de novas unidades agroindustriais. Com base no ZAC, a Companhia Nacional de Abastecimento 
Tramas

$y$ Redes

Dic. 2021

$\mathrm{N}^{0} 1$

ISSN en

trámite

(Conab) mapeou as áreas de tensão ecológica, em virtude da expansão do setor canavieiro para os biomas da Amazônia e do Pantanal.

O ZAC, basicamente, limitou o plantio de cana nas áreas de ocorrência da Floresta Amazônica, no Pantanal e na Bacia do Alto Paraguai (BAP). O Pantanal ocupa áreas de dois estados brasileiros, a saber, Mato Grosso (MT) e Mato Grosso do Sul (MS). A BAP contém o bioma Pantanal, cuja área é de aproximadamente $250 \mathrm{mil} \mathrm{km2.}$

Levando em consideração que a BAP é constituída por áreas tanto de planalto quanto de planície, a prática agrícola verifica-se com mais intensidade nos planaltos adjacentes à planície pantaneira. De acordo com Goltz et al. (2011, p. 28), a erosão, as alterações no fluxo hidrológico, contaminação do lençol freático pelo uso de agrotóxico e a deposição de sedimentos nas planícies são os principais impactos da expansão da sojicultura e da lavoura canavieira sobre as áreas de planaltos que compõem a BAP.

Após a ascensão da extrema-direita no Brasil, em 2019, as políticas de proteção ambiental têm sido flexibilizadas com o propósito de fomentar a incorporação, pelo agronegócio, das terras indígenas e das unidades de conservação. As consequências do afrouxamento da legislação têm sido os incêndios que assolam a Floresta Amazônica e o Pantanal, que perderam

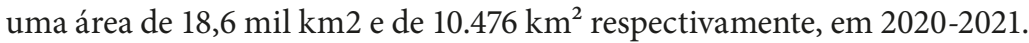

Acrescido aos desmatamentos, observa-se nos últimos cinco anos que houve mudanças no regime pluviométrico na região da $\mathrm{BAP}$, com estiagens mais prolongadas. Na altura do município de Cáceres-MT, um dos que mais perderam vegetação por queimada entre 1985 e 2020, o nível do rio Paraguai atingiu $54 \mathrm{~cm}$ no último dia 5 de agosto de 2021. A redução da calha de navegação da Hidrovia Paraguai-Paraná já impacta o escoamento da soja e do minério de ferro pelos portos fluviais localizados em Puerto Soarez (Bolívia), Corumbá (Brasil), Rosário (Argentina), entre outros. A crise hídrica que atinge toda a Bacia do Rio da Prata já dificulta a logística da sojicultura, e os incêndios verificados no Pantanal e na Floresta Amazônica mesclam a ação antrópica e a seca agravada pela estiagem.

O Projeto de Lei n. ${ }^{\circ}$ 2633/2020, que tramita na Casa Legislativa Federal do Brasil - conhecido também como "PL da grilagem" - facilita a marcha do capitalismo predatório, impulsionado pela cúpula de extremadireita que governa o país. Em linhas gerais, o "PL da grilagem", caso aprovado, possibilitaria a regularização de terras desmatadas, sobretudo nas regiões de grande biodiversidade. Outra questão diz respeito à tese do marco temporal para demarcação de terras indígenas.

A bancada ruralista do Congresso e o Poder Executivo do Brasil, com o intuito de agradarem a setores do agronegócio favoráveis à expansão da área agrícola, defendem que os indígenas só tenham direito à demarcação das terras nas quais já estivessem antes de 5 de outubro de 1988, data da 
promulgação da Constituição. Considerando o conteúdo do projeto de Lei n. ${ }^{\circ}$ 2633/2020 e a defesa do marco temporal para demarcação de terras indígenas, pode-se inferir que o aumento no número e na extensão dos incêndios no bioma Pantanal e na Floresta Amazônica tenha sido motivado pela proposta de regularização fundiária defendida pelo atual governo federal.

No entanto, as tradings que controlam a cadeia produtiva da soja, da cana, dentre outras commodities, posicionaram-se contra o "PL da grilagem" e têm pressionado os deputados a não aprovarem, uma vez que as barreiras não tarifárias de cunho ambiental dificultariam a exportação, para a UE, dos produtos advindos de regiões de alta biodiversidade. A Cargill, com o objetivo de não comprar soja que tenha sido produzida em área ilegal, por exemplo, mapeou todas as fazendas localizadas na região do Mapitoba que fornecem grãos para serem processados.

As implicações geopolíticas para o Brasil em decorrência dos incêndios no Pantanal e na Floresta Amazônica traduzem-se na possibilidade de sanções econômicas e/ou boicotes aos produtos brasileiros no mercado global. Além disso, observa-se a deterioração internacional da imagem do Brasil na atual conjuntura. Anteriormente à ascensão da extrema-direita ao governo central, o Brasil era tido como país que desenvolveu os princípios da boa diplomacia, que se caracterizava como pragmática, pautada na defesa dos princípios multilaterais e no emprego do soft power, como afirma Lima (2009).

No plano da política externa brasileira, o abandono da diplomacia pragmática e o alinhamento unilateral aos interesses dos EUA tornam o atual corpo político brasileiro isolado na cena internacional. E no plano das políticas domésticas, os desmatamentos e incêndios na Amazônia, no Pantanal, por exemplo, comprometem os interesses das empresas transnacionais que operam no segmento do agronegócio, por conta das barreiras não tarifárias de cunho ambiental. Ainda ampliam os conflitos entre as populações tradicionais que têm tido suas terras invadidas por ruralistas com apoio governamental.

Desta feita, os efeitos imediatos dessa corrida global por recursos energéticos e alimentares, como se nota, tem sido a intensificação do processo de concentração da terra, da expansão das lavouras e cultivos destinados para o mercado global, em especial para o mercado chinês e para o europeu, sobre as áreas de pastagens degradadas, o que tende a empurrar a pecuária para o bioma da Amazônia e a reduzir a área para a produção de alimentos.

Em 1990, no Brasil, a área plantada com feijão era de 5,3 milhões de hectares. Em 2019 o feijão ocupou apenas 2,7 milhões de hectares, ou seja, uma redução de $47 \%$ em termos de área, segundo os dados do IBGE. Em 2012 e 2018, o Brasil chegou a importar feijão da China, em decorrência 
da quebra de safra provocada por variação climática. Não obstante, a concentração da terra deve ser encarada como um dos principais motivos que comprometem a soberania alimentar no Brasil e nos demais países sul-americanos. Conforme argumentou Gonzáles (2014, p. 10), a monocultura da soja tem drenado as riquezas para um grupo pequeno de corporações transnacionais e tem reduzido a diversificação dos cultivos de primeira necessidade no Paraguai e no Uruguai; tendências também verificadas na Argentina e na Bolívia, conforme demonstraram Zanotto (2017) e Costantino (2019).

Outro fato é que o cultivo de gêneros agrícolas de primeira necessidade tem-se localizado cada vez mais distante das regiões onde está grande parte da população. Por essa razão, o escoamento das zonas produtoras para as demais regiões fica comprometido em decorrência dos problemas de infraestrutura e logística, além do que a malha viária é insuficiente, de péssima qualidade e, no caso de existir pedágio, este é caro em relação às enormes distâncias que o produto tem de percorrer.

Em 2019, o arroz foi um dos produtos alimentares que mais pressionou a inflação para cima, uma vez que o estado do Rio Grande do Sul, atualmente, responde por $70 \%$ de toda a produção daquele grão no Brasil. Em 2004, respondia por 45\% da produção. Então, o que se observa nas novas dinâmicas territoriais em relação à expansão da monocultura é que a produção de alimentos está distante dos centros consumidores e tem ocasionado forte pressão inflacionária.

Ainda em 2019, o valor da produção gerado pelo cultivo do feijão e arroz, no Brasil, foi de R\$ 7,4 e R\$ 8,2 bilhões respectivamente. Já o valor da produção da cana-de-açúcar e da soja, naquele mesmo ano, foi de R\$ 54 e R\$ 125 bilhões respectivamente. Os cultivos mais valorosos, portanto, continuam a ser aqueles que estão vinculados com a produção da soja. É por essa razão, entre outras, que a América do Sul, apesar de ser uma das maiores fronteiras agrícolas do mundo, ainda não possui soberania alimentar, uma vez que a produção de alimentos ocorre longe dos centros consumidores e sua arena de produção é reduzida ano após ano, concorrendo para a elevação dos preços.

$\mathrm{E}$, por fim, é preciso ressaltar que os regimes pluviométricos e hidrológicos são interdependentes. O continente sul-americano e suas regiões produtoras de grãos dependem dos rios voadores, cujo processo de formação está vinculado à manutenção da Floresta Amazônica, que presta serviços ambientais insubstituíveis, como explicou Nobre (2014):

[...] nos últimos 40 anos, a última grande floresta, a cabeceira das águas atmosféricas da maior parte do continente, esteve sob o ataque implacável do desmatamento. Coincidentemente, aumentam as perdas com desastres naturais ligados a anomalias climáticas, tanto 
por excessos (de chuva, calor e ventos), quanto por falta (secas). As regiões andinas, e mesmo da costa do Pacífico, que dependem do derretimento das geleiras para seu abastecimento de água, estão sob ameaça, já que quase toda a precipitação nas altas montanhas, que suprem as geleiras ano a ano, tem sua matéria-prima no vapor procedente da floresta amazônica. A leste dos Andes, a escala da dependência do ciclo hidrológico amazônico é incomensuravelmente maior. As regiões de savana na parte meridional, onde há hoje um dos maiores cinturões de produção de grãos e outros bens agrícolas, também recebe da floresta amazônica vapor formador de chuvas. Não fosse também a língua de vapor que no verão hemisférico pulsa da Amazônia para longe, levando chuvas essenciais, seriam desertos as regiões Sudeste e Sul do Brasil (onde hoje se encontra sua maior infraestrutura produtiva) e outras áreas como o Pantanal e o Chaco, as regiões agrícolas na Bolívia, Paraguai, Uruguai e Argentina. (Nobre, 2014, p. 7, grifo nosso)

Economistas brasileiros de diversas matizes de pensamento - dos liberais aos keynesianos entre outros -, ambientalistas e organismos internacionais, como a Organização das Nações Unidas (ONU), exercem pressão para que ações efetivas para conter o desmatamento florestal sejam tomadas pelo governo brasileiro para evitar a savanização da Amazônia que impactará, conforme alertou Nobre (2014), o cinturão agrícola da América do Sul.

\section{Considerações finais}

O modelo de expansão da fronteira agrícola verificado nos países da América do Sul é gerador de tensões socioespaciais, tanto no plano doméstico quanto no plano das relações internacionais. Para estudiosos da cadeia produtiva da soja, é mais vantajoso que o agronegócio se norteie por um paradigma desenvolvimentista incentivando empreendedores domésticos a participarem das etapas que melhor remuneram o capital e o trabalho num contraponto à hegemonia das tradings transnacionais que se apropriam de ganhos que não se capilariza no interior dos países produtores daquele grão.

Considerando o contexto das mudanças climáticas, as políticas territoriais dos países sul-americanos devem incorporar os pressupostos do desenvolvimento sustentável, não apenas no discurso, mas nas estratégias de governança, de modo a contemplarem os diferentes segmentos sociais e seus interesses, sem desconsiderar as pressões de atores que operam na escala internacional, como outros Estados Nacionais, corporações transnacionais etc. A política de promover a flexibilização do controle ambiental engendra a expulsão dos povos originários de suas terras e agrava os problemas 
ambientais, sobretudo nas áreas pressionadas pela expansão agrária, como é o caso do bioma Pantanal.

Líderes políticos europeus como Emmanuel Macron, Presidente da França, e Ângela Merkel, Primeira-Ministra da Alemanha, têm feito duras críticas ao governo brasileiro por este flexibilizar as políticas ambientais e apoiar a expansão da produção agropecuária sobre terras indígenas e sobre áreas de florestas. Como demonstramos, as tradings que operam na cadeia produtiva da soja, para se certificarem que a produção não ocorreu em área ilegal têm mapeado as fazendas que fornecem os grãos. Do contrário, poderão ser impedidas de exportarem soja in natura para os países europeus em decorrência das barreiras não tarifárias de cunho ambiental.

Um dos caminhos possíveis para conciliar a geração de energia de baixo carbono a partir de cultivos agrícolas sem comprometer a soberania alimentar seria produzir agrocombustíveis de segunda geração e terceira geração. $\mathrm{O}$ etanol celulósico, derivado de qualquer tipo de biomassa, tem a vantagem, por exemplo, de não requerer mais terra para expandir a produção, como é o caso dos agrocombustíveis de primeira geração que demandam matérias-primas como a soja, o milho, a cana-de-açúcar etc.

Por fim, a produção de alimentos nos países da América do Sul merece atenção. Como se demonstrou, na medida em que as culturas de cana e soja se expandem, as culturas de feijão, arroz, mandioca, batata entre outras, têm as suas áreas reduzidas. E, de fato, levando em consideração a área agricultável da região sul-americana seria possível conciliar a produção de alimentos com a produção de energia de baixo carbono. Mas, o agronegócio da soja e dos agrocombustíveis, como se demonstrou, tem se tornado cada vez mais desnacionalizado e oligopolizado. E mais. São segmentos que objetivam concentrar mais a terra e recursos hídricos.

\section{Referências}

Adecoagro (2021). https://www.adecoagro.com/pt [página web]. Brasil. Agnew, John e Corbridge, Stuart (1995). Mastering space: hegemony, territory and international political economy. London/New York: Routledge.

Archer Daniels Midland [ADM] (2021). https://www.adm.com/adm-worldwide/brazil-pr [página web]. Brasil.

Associação Brasileira dos Produtores de Soja [Aprosoja] (2021). https://aprosojabrasil.com.br/ [página web]. Brasil.

Bernardes, Júlia Adão (2015). Novas fronteiras do capital no cerrado: dinâmica e contradições da expansão do agronegócio na região Centro-Oeste, Brasil. Scripta Nova (Barcelona), 507, 1-28.

Bunge Limited (2021). https://www.bunge.com.br/ [página web]. Brasil. 
Cargill (2021). https://www.cargill.com.br/ [página web]. Brasil.

Castells, Manuel (2018). Ruptura: A crise da democracia liberal. Rio de Janeiro: Zahar.

Tramas

Costantino, Maria Agostina (2019). Da insegurança à dependência alimentar: padrão de acumulação e apropriação de terras na Argentina. Paraíba: Universidade Federal da Paraíba.

Cunha, Roberto César e Espíndola, Carlos José (2015). A dinâmica geoeconômica recente da cadeia produtiva da soja no Brasil e no mundo. GeoTextos, 11(1), 217-238.

Datagro (2021). https://www.datagro.com/ [página web]. Brasil.

Dos Santos, Fabio Luis Barbosa (2017). República Unida da Soja: brasileiros e agronegócio no Paraguai e na Bolívia. Em Anderlei Vazelesk Ribeiro e María Verónica Secreto (orgs.), Agrarismos-Estudos de História e Sociologia do Mundo Rural Contemporâneo. Rio de Janeiro: Mauad X.

Freitas, Elisa Pinheiro de (2013). Território, poder e biocombustíveis: as ações do Estado brasileiro no processo de regulação territorial para a produção de recursos energéticos alternativos [Tese de doutorado]. Universidade de São Paulo, Brasil.

Freitas, Elisa Pinheiro de e Queirós, Margarida Maria (2018). O circuito produtivo dos agrocombustíveis no Brasil sob a ordem do liberalismo transnacional: do controle estatal à hegemonia corporativa. GEOUSP Espaço e Tempo, 21(3), 771-792.

Freitas, Elisa Pinheiro de; Rossini, Rosa Ester e Queirós, Margarida (2014). O poder das empresas transnacionais sobre o território brasileiro. Reflexões a partir do sector sucroenergético. XIII Colóquio Internacional de Geocrítica: el control del espacio y los espacios de control, Barcelona. https://d1wqtxts1xzle7.cloudfront. net /39698659/XIII_Coloquio_Internacional de_Geocrtica20151104-14818-yxxzwb.pdf?.

Goltz, Elizabeth et al. (2011). Expansão de cana-de-açúcar e manejo da colheita na região da Bacia do Alto Paraguai. Revista GeoPantanal (UFMS/AGB), (10), 27-36.

González, Rafael Dário (2014). A estrutura produtiva da soja e seus impactos: um estudo comparativo entre Paraguai, Argentina e Uruguai. Revista Iniciativa Econômica, 1(1).

Houtart, François (2010). A agroenergia. Solução para o clima ou saída da crise para o capital? Petrópolis: Editora Vozes.

Lima, Maria Regia Soares de (2009). Brasil como país intermediário e poder regional. Em Andrew Hurrel et al., Os Brics e a ordem global. Rio de Janeiro: Editora FGV.

Mapbiomas (2021). https://mapbiomas.org/ [página web]. Brasil. 
Medina, Gabriel da Silva (2021). Economia do agronegócio no Brasil: participação brasileira na cadeia produtiva da soja entre 2015 e 2020. Novos Cadernos NAEA, 24(1).

Medina, Gabriel da Silva; Guimarães Ribeiro, Gessyane e Madureira Brasil, Edward (2015). Participação do capital brasileiro na cadeia produtiva da soja: lições para o futuro do Agronegócio Nacional. Revista de Economia e Agronegócio/Brazilian Review of Economics and Agribusiness, 13(822-2016-54285).

Nobre, Antonio Donato (2014). O futuro climático da Amazônia. Relatório de Avaliação Científica. São José dos Campos, São Paulo. http:// awsassets.panda.org/downloads/o_futuro_climatico_da_amazonia_versao_final_para_lima.pdf.

Oliveira, Luiz Roberto Gomes Dias de (2009). Barreiras ambientais e seu impacto nas exportações brasileiras [Monografia de especialização]. Universidade Federal do Rio Grande do Sul.

Panith, Leo e Gindin, Sam (2012). The making of global capitalism: The political economy of American Empire. London/New York: Verso.

Peet, Richard (2007). Geography of power: the making of global economy policy. London/New York: Zed Books.

Saath, Kleverton Clovis de Oliveira e Fachinello, Arlei Luiz (2018). Crescimento da demanda mundial de alimentos e restrições do fator terra no Brasil. Revista de Economia e Sociologia Rural, 56, 195-212.

Soares, Raimundo Christian Oliveira (2019). O mercado da soja no Paraguai: expansão, consolidação e momento atual. Colóquio-Revista do Desenvolvimento Regional, 16(3), 211-231.

Stiglitz, Joseph (2004). Globalização. A grande desilusão [Tradução de Maria Filomena Duarte. 3. ed.]. Lisboa: Terramar.

Wesz Junior, Valdemar João (2014). O mercado da soja no Brasil e na Argentina: semelhanças, diferenças e interconexões. Século XXI: Revista de Ciências Sociais, 4(1), 114-161.

Zanotto, Rita (2017). Soberania alimentar como construção contra-hegemônica da via campesina: Experiências no Brasil e na Bolívia [Tese de mestrado]. Programa de Pósgraduação em Desenvolvimento Territorial na América Latina e Caribe (TerritoriAL), Universidade Estadual Paulista “Júlio de Mesquita Filho" (UNESP), São Paulo, Brasil. 